\title{
Global jams and country-specific adjustments: insights from Iran
}

\author{
Bijan Aryana*
}

Lancaster Institute for the Contemporary Arts, Lancaster

University,

LICA Building, Lancaster, LA1 4YW, UK

Email: b.aryana@lancaster.ac.uk

*Corresponding author

Saleh Baradaran Amini

Department of Psychology,

Faculty of Psychology and Education, Shahid Beheshti University,

Daneshjou Boulevard, Tehran, 1983969411, Iran

Email: s_baradaran@sbu.ac.ir

\begin{abstract}
Service and sustainability jams are annual events that are being held across the globe to promote collective design-based problem solving. These events, similar to other innovation jams represent a new approach towards design which is based on collective and distributed innovation. While the online platform and the main framework of these jams are designed by the global organizers, there are always country-specific adjustments in implementation. Understanding the relationships between the global frameworks and the country-specific adjustments in these collective innovative activities is an interesting, but unexplored research area. This paper explains how seven jam events between 2012 and 2015 in Iran have been influenced by changes on both global and country-specific levels. As a conclusion, we found out that despite the important role of global frameworks, countryspecific adjustments had a significant influence on the tools, rules and procedures, roles, demographics of participants, and the resultant designs.
\end{abstract}

Keywords - service jams; sustainability jams; innovation jams; country specific design; Iran; distributed innovation; collective innovation; activity theory; constant comparative analysis. 


\section{Introduction}

Jams are contemporary practices that have not been explored much in the design and innovation literature (Diasio and Bakici, 2010). The term "jam" was first coined by the American jazz music community in the 1920s for the non-commercial gatherings aiming at jazz improvisations, exchanging experiences, and extending community networks (Berliner, 1994). After expansion of the online networks in the $21^{\text {st }}$ century, the jam concept was used for online innovation activities with similar processes and objectives. The early examples of this type of jams were organized by global corporations as a technique for harvesting ideas (Pearson, 2011). These innovation jams enabled all members of the organizations to participate in solving problems and making decisions regardless of their positions (Huff et al., 2013). This characteristic made jams suitable for non-profit activities with societal objectives. Non-profit jams are among the interesting examples of social design, which has not been discussed much, especially by the design research community.

An interesting feature of the jams is their combined global and local essences. While a wide range of participants from different countries can collaborate in a jam, their local perspectives affect their solutions for the same problem (Larsen et al., 2011). This is not only limited to the non-profit jams but also can be seen in the business oriented jams (Bjelland and Wood, 2008). Local, cultural or country-specific differences and their relationships with contemporary trends like globalization and internationalization have drawn attention of many design researchers. However, in most cases their research studies address conventional forms of design practice or education. Non-profit jams represent a new type of global-local dynamics in a voluntary social context which is not similar to the traditional business or educational contexts.

The scope of this work is relationships between the global infrastructure of jams and countryspecific adjustments made by local organizers. For this purpose, we will look at seven successive jams in Tehran, Iran; and see how these jams have evolved through the years. As explained, jams can be considered as tools for social design, and at the same time they represent a form of future crowd collaborative work (Callaghan, 2014). There are few research studies about social design in countries like Iran. Iran has a unique political system and is among the economies having a high potential of becoming among the world's largest economies in the 21st century (O’Neill and Stupnytska, 2010). Dominance of Persian language and Shia Islam distinct Iran from its neighbouring countries (Rubin, 2012) and at the same time its political tensions with the West after the 1979 revolution have prevented it from integrating with the global economy (Ghorashi and Zangeneh, 2014). These characteristics make Iranian society quite different, not only from the Western societies, but also from the other countries in the same geographic region. Therefore, looking these social design practices in Iran will give us new insights about how such concepts can be applied to societies with unique characteristics.

Global Service Jam (SERJ) and Global Sustainability Jam (SUSJ) are being annually held in Iran since 2012. At the time of writing this article, four rounds of Global SERJ and three rounds of Global SUSJ have been conducted in Tehran, the capital of Iran. The information available from these jams was our main source of understanding this contemporary practice in Iran. The first jam was held in 2012 and the last one occurred in 2015. Therefore, we were 
able to see how country-specific issues gradually have affected this practice through the years. Considering this context, we posed our central research question:

RQ1: How did Tehran SERJs and SUSJs evolve between 2012 and 2015?

To make our question more specific, we defined our sub questions concerning the fact that country-specific adjustments and design implementations were our main focus points:

RQ2: How did the country-specific adjustments affect the jams' evolution?

RQ3: How can experiences of these country-specific jams help other local organizers to make effective country-specific adjustments in similar social design events?

All of our research questions begin with "how"; the central research question addresses the topic from a generic point of view while associated sub-questions highlight our scope. These characteristics suggest that a qualitative approach can be suitable for our research (Creswell, 2014). Using this approach enabled us to have a closer look at jams in a country-specific context without aiming to generalize our findings.

The rest of this article is organized as follows: The related works section reviews some of existing research studies about jams. Then the methods section explains how we developed a framework for analysing and comparing jam events based on the activity theory and a three steps qualitative analysis. Accordingly, the results section exhibits the main results of the study. In the discussion section, we will see how results can be compared with some related works, and how these results can be used for answering the research questions. The conclusion section particularly explains the answers of the research questions. Finally, we will look at the limitations of our work in the research limitation section.

\section{Related works}

In this section we first look at the early examples of innovation jams. Then, we explain the concept of non-profit jams. Moreover, some theoretical aspects of jams such as their role in democratized innovation and future design projects are addressed briefly. Finally, we discuss the challenges of implementing ideas generated in jams.

\subsection{Early examples of innovation jams}

In general, most innovation jams are based on online platforms; however, there are examples of jams in which users and developers of a product attended a real idea generation session, similar to the conventional music jams (Bosch-Sijtsema and Bosch, 2014). One of the early experiences of a global innovation jam was an online brainstorming among the IBM's employees around the world in 2001, called as IBM's World Jam, (Helander et al., 2007). IBM used the experiences gained from the World Jam in its next innovation jam in 2006, which was planned for funding a number of promising ideas to fill the gap between the new technologies and the unfulfilled customer needs (Bjelland and Wood, 2008; Helander et al., 2007). 
Bjelland and Wood (2008) describe an inside view of the IBM's jam in 2006. This jam was quite influential in terms of defining a model for jams (Corsi and Neau, 2015), which was then used in many different contexts such as non-profit jams. The IBM's first jam was highly dependent on the online tools that enabled the IBM employees and other stakeholders to express and share their ideas. Of course, a number of experts were involved in clustering and filtering the ideas. This online brainstorming in a global company revealed different countryspecific approaches towards similar problems. For example, in response to the "personal health care record" topic, American participants were concentrated on improving the medical system's efficiency. In contrast, the Chinese and the Indians were more interested in covering all groups of people by their medical systems (Larsen et al., 2011). Another interesting aspect of the IBM's innovation jam is its technological and methodological evolution between 2001 and 2009 (Diasio and Bakici, 2010). In order to manage many participants, the technological platform was redesigned in a more organized way with additional steps and requirements. External stakeholders such as academics were added, and management system was convinced to show more commitment to open and collaborative work.

\subsection{Non-profit jams}

Global SERJ is an annual jam, in which people interested in using a design-based problem solving approach collaborate towards an online network to generate ideas for new services. These ideas should be developed based on a shared theme in 48 hours (What's a Jam?, 2015). The outcomes of this global practice can have a local focus. An example is a digital service called "ArtiSino: Celebrating Chinese Artisans". This service was designed in Global SERJ2012 to bring customers to traditional Chinese artisans (craftsmen) and preserve Chinese craftsmanship from decline (Barra, 2012).

Römer et al. (2011) reviewed the Global SERJ 2011 and identified a number of its unique characteristics. For example, unlike the IBM's Jams, Global SERJs do not belong to a commercial organization and all of their contents are open access.

Lo (2014) have looked at one of the services resulted from Global SERJ in 2013. This service is called "Eat Me!" and helps users to grow fruits and vegetables in their home gardens, exchange their experiences, and share the final products. This service benefits from the hybrid touchpoints that interweave the online and offline touchpoints, and facilitate real life experiences using online infrastructures.

Global SUSJ has a similar process to Global SERJ, and is defined as a design-based approach to creativity (What's a Jam?, 2015) for developing sustainable solutions around the world. Although sustainable design became a popular notion in the recent decades, applying sustainability principles in the real contexts has been always a challenge for designers. McMahon and Bhamra (2012) suggest that sustainable designers should learn new skills for International collaborative projects such as Global SUSJs.

\subsection{Democratized innovation}

Laubacher (2012) describes the evolution of innovation since the beginning of the $20^{\text {th }}$ century, and the way that innovation has transformed from a centralized process to a fully 
distributed activity. Jams as collective intelligence activities belong to the most recent generation of innovation.

According to Peschl and Fundneider (2014), our understanding of innovation as a mechanical knowledge creation process should be changed, and we should move towards a new concept called enabling spaces. Enabling spaces consist of multiple dimensions such as architecture, technology, society, cognition, organization, and emotion. In enabling spaces, innovation can be defined as a "highly challenging social and epistemological process which needs supporting (infra-) structures facilitating and enabling these processes." They claim that meaning is the only reality that matters in the enabling spaces.

Innovation jams are developed to bridge technology, innovation and people. Therefore, they can be considered as an example of social design (Laubacher, 2012), especially because of their democratized innovation process (Lo, 2014; Römer et al., 2011).

\subsection{Jams as future design tools}

Jams can facilitate participatory prototyping as a contemporary design tool, in which the activity of simulating the sense of the future by storytelling, and demonstration of use is often more important than the final prototype (Van Waart et al., 2015). Callaghan (2014) classifies jams as a type of crowdsourcing, which is a common technique for second generation research and development projects. Crowdsourcing techniques can be successful when certain requirements have been fulfilled (Stieger et al., 2012). The first requirement is diversity of participants that can guarantee the newness of inputs. Another requirement is the proper method for summarising the participants' inputs. Finally, participants must have enough freedom and a high level of independence.

Carlsson et al. (2015) explain how they used jams to facilitate the communication between industry professionals and sustainability experts in the IT sector. They believe that setting and surrender of control, skills of participants, and structure of events can define the success of jams.

\subsection{Implementation challenge}

As explained, a number of scholars see jams as a promising futuristic tool. However, the evidences show that in some sections of the industry jams have already their own place in the innovation strategies, and use of them is not only limited to the IT sector. Turkel and Theodorakopoulou (2015) show how a large established multinational company in the automotive industry uses jams in their open innovation process that includes ideation and concept development steps. Similar to the IBM innovation jam, this activity is limited to the people within the organization.

Another study on automotive industry shows how Renault and Volvo use in-house online contests in their innovation processes (Elerud-Tryde and Hooge, 2014). Elerud-Tryde and Hooge (2014) suggest involvement of external stakeholders and cross-disciplinary collaboration between different departments to cope with the implementation challenge of the ideas. Ende et al. (2014) identify two main reasons behind this challenge. First, the organizers 
may miss some high quality and feasible solutions because of dealing with many ideas. The second reason is the freedom of the participants in generating ideas that makes the idea generation step fuzzy.

According to Keinz et al. (2012) there should be a clear link between the problem definition and the final evaluation criteria. The control process and the available tools for idea generation also must act as guidelines for generating relevant ideas.

Birkinshaw et al. (2007) address communication difficulties in discontinuous innovations networks. Discontinuous innovations represent a completely new pattern in market or industry or even in both (Hewing, 2014). In most cases, such innovations are the results of collaborative networks, inside or outside of organizations. Therefore, finding the right partners in these networks, defining suitable relationships between them, and managing the communication within the networks are three main obstacles. Unlike conventional innovation approaches, organizations should try to trust the partners, because sharing some internal information will cause receiving more external information (Birkinshaw et al., 2007).

As the above examples suggest, most references concentrate on the outcomes of existing jam activities rather than theoretical discussions about their platforms and infrastructures. Ziaie (2014) tried to fill this gap, and proposed a design guideline for open production communities. In these communities, voluntary participants provide policies and technologies to facilitate the process of generation, evaluation, distribution, and governance of contents. The organizers can initially form the features of an open production community, such as technical features or collaboration rules. However, in order to finalize these features, organizers need to test these features in at least two communities. The first community is the source community, where the initial idea for collaboration comes from, and the second community is the target community, where outsiders are being encouraged to generate content. Features that can work well in both communities are perfect for the final design, because they are not context dependent.

\subsection{Summary:}

Our review on some related works can be summarized as follows:

\subsubsection{Diversity of terms:}

Terminology used for describing jams is still developing, and therefore can be ambiguous. Jams are associated with a wide range of concepts including collective intelligence, crowdsourcing, design-based creativity, discontinuous innovation, enabling spaces, the next generation research and development, open production communities, participatory prototyping, social design, and social innovation.

\subsubsection{Organizational and non-profit jams:}

We can identify two categories of jams. One category includes jams that are managed by organizations for their own objectives. IBM, Volvo, and Renault jams are examples of organizational jams. These jams are often based on online collaborative activities and have an 
internal focus. The overall goal is harvesting innovative ideas similar to design contests. The other category includes non-profit jams such as Global SERJ and Global SUSJs. These jams are not usually competitive and are initiated by individuals. There is no organizational goal or control over the process.

\subsubsection{Innovation versus design:}

Existing literature about jams often viewed them from the innovation perspective. The design perspective is only used few times when non-profit jams are discussed. In other words, knowledge about jams comes from the innovation management domain, and jams are not explored much in design research.

\subsubsection{Implementation limitations:}

Implementation can be one of the main challenges of jams. Following aspects of jams can affect the implementation:

- Organizing jams: Jams are practice-based activities and usually evolve based on the empirical evidences. Some references suggest an organized process with detailed steps to avoid generating irrelevant solutions, while some others suggest more freedom and selforganizing possibilities.

- Jam participants: While diversity of participants can facilitate idea generation, there are some concerns about the intellectual property in organizational jams. Moreover, diversity of participants sometimes can mislead the process from its objectives. However, this challenge is less sensitive for non-profit jams, and these jams can easily benefit from a wide range of participants.

- Information flow: Facilitation of information exchange can improve the quality of ideas. Participants should understand the most critical aspects of the problem. If a jam is formed as a contest, there should be clear links between evaluation criteria and problem definition.

- Jams as a futuristic tool: Jams show an example of future collaborative crowd projects based on technological platforms, and free of the conventional organizational hierarchies. Therefore, collaborating in jams is an effective soft skill that can be taught in design programs.

- Socio-cultural aspects of jams: Jams exhibit a democratic way of proposing ideas, in which good ideas from anybody can have a chance to become a reality. Jams are a form of distributed innovation that can bring innovation to the society rather than keeping it in certain organizations. Although jams usually have a global online platform, they can provide opportunities for local improvements by encouraging people to solve the problems of their own socio-cultural contexts.

\section{Method}

Based on the research questions, this study is about Tehran SERJs and SUSJs as repeating and evolving activities. According to the experiences of each jam, both global and local organizers had this possibility to make some adjustments in the next year's jam. Therefore, there are some similarities between this work and action research, as most definitions of 
action research describe it as doing research for the sake of taking action (Craig, 2009). These definitions also indicate that the action researcher should be a practitioner as well, and research should not be separated from the action (Craig, 2009; Sohng, 1996). In this research, data gathering and analysis steps were conducted by one of the authors who has been also a local organizer of all Tehran SERJs and SUSJs since 2012. Of course, if we had access to more rounds of each jam, it was preferable to focus on just one jam, as SERJs and SUSJs had some differences, especially in terms of their objectives.

Diverse types of data were available from the jams, so a proper framework for understanding and comparing actions was needed. One of the compatible frameworks for doing such kind of investigations in action research results from the activity theory (Edwards, 2000). In order to explain the activity theory in a simple and applicable way, Engestrom (2000) developed a framework showing the basics of an activity (figure 1). In his model, the outcome of an activity (object) depends on some contextual factors, including tools used for the activity, subject of the activity, rules of performing the activity, involved community, and division of labour. Any change in each factor, will change the object as the outcome of the activity. As a result, we developed an adapted version of Engestrom's framework for the jams that can be seen in figure 1.
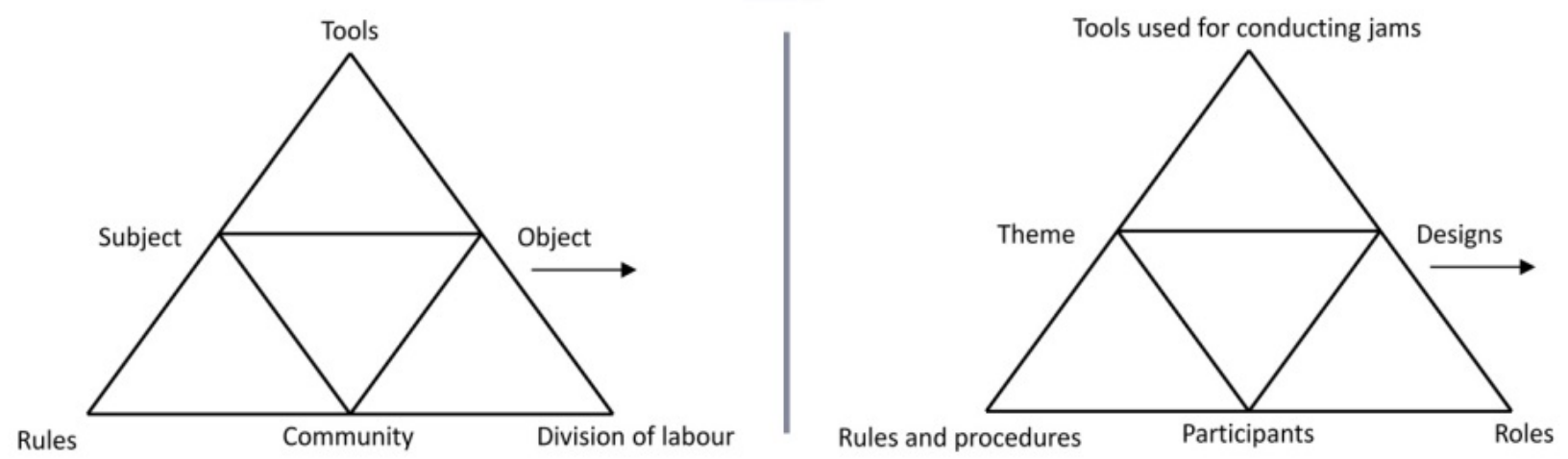

Figure 1. Engestrom (2000) framework (left) and our initial corresponding framework for jams (right)

Moreover, according to the existing literature we realized that some additional aspects of jams especially the implementation of ideas should be considered as well. As explained, implementation of the ideas was one of the main challenges of jams. The solutions for implementation were classified in three categories including organizing jams, jam participants, and information flow. The Engestrom (2000) framework addresses organizing jams (by rules) and jam participants (by community), but there is no separate factor for exhibiting information flow. Therefore, we added information flow to our list for investigation. Considering the strong socio-cultural aspect of jams and our focus on countryspecific adjustments, we tried to separate country specific factors from global ones. In conclusion, we used an adopted version of the Engestrom (2000) framework shown in figure 2. 


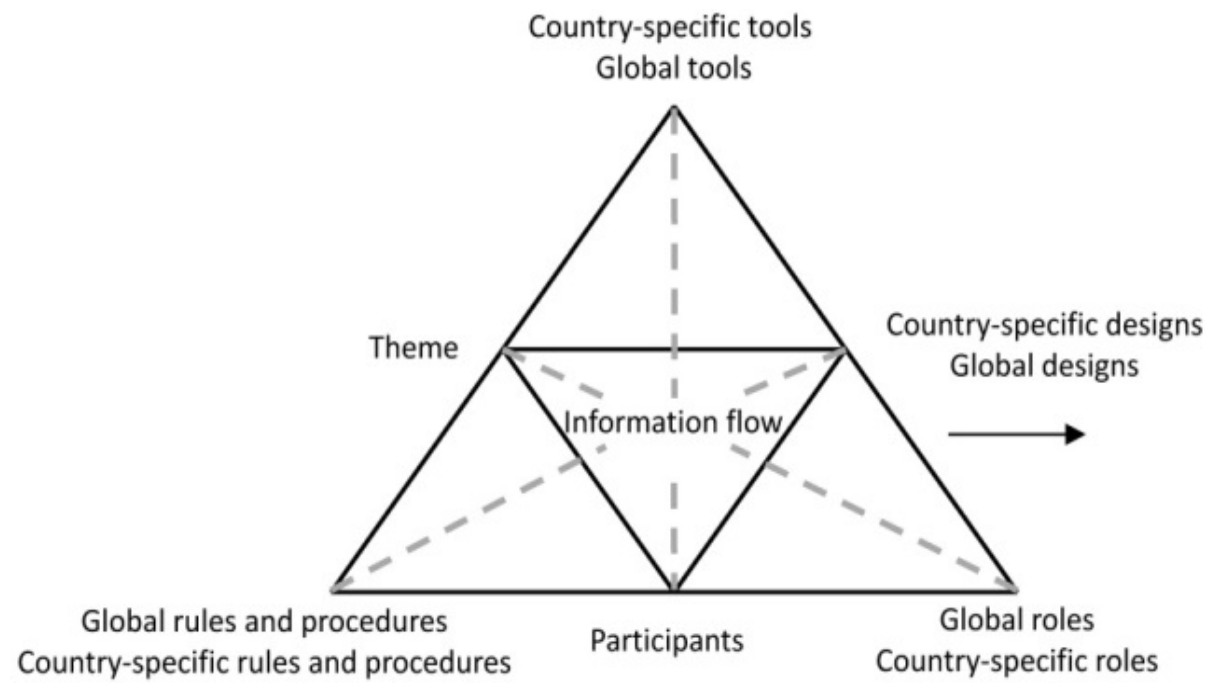

Figure 2. Final adopted activity framework

Various sources of data were available from four SERJs and three SUSJs. These data types were not uniformed; therefore we conducted a three step qualitative analysis to be able to draw connections between findings and making meaningful conclusions. The steps of qualitative analysis include gathering and reducing data, displaying data, and drawing conclusions (Huberman, and Miles, 1994). In the first and second steps, the framework exhibited in figure 2 helped us to organize our findings about activities in each jam. In the third step, we used constant comparative analysis (Harding, 2013) to compare the jams and answer the research questions. Figure 3 shows a summary of the research method, and the next subsections explain the research method in more detail. 


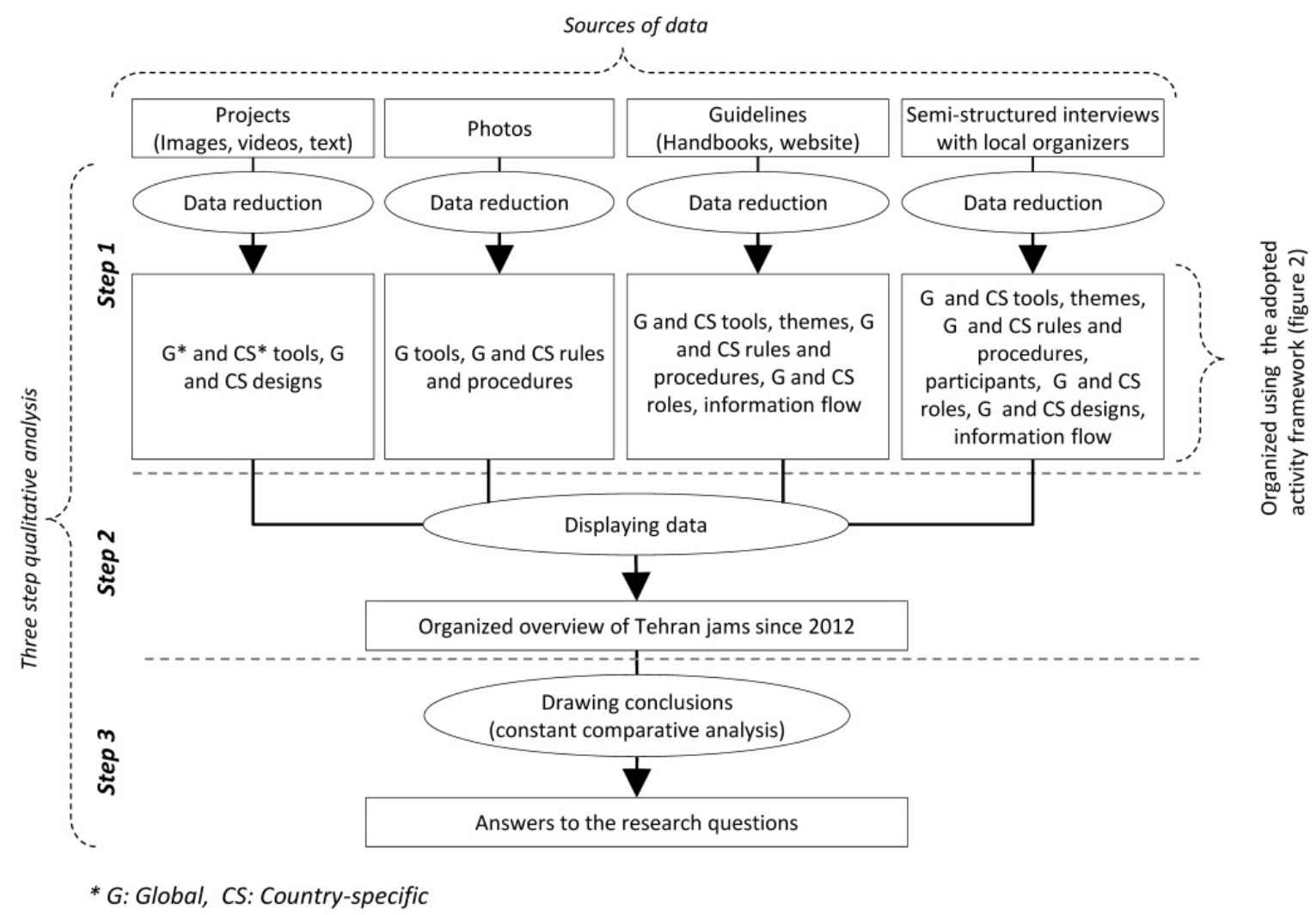

Figure 3. Summary of research method

\subsection{Step 1 of qualitative analysis, data gathering and reduction}

In general, five sources of data were available from seven rounds of Tehran jams since 2012. These were gathered and reduced in this way:

1. Projects: These include Images, videos and textual contents generated by participants to explain their designs on the jams' websites. We classified the designs into countryspecific and global categories. We also identified the techniques used.

2. Photos: These were taken by the organizers showing the steps passed by each group of participants. These were used for identifying the rules, procedures, and the tools used in each jams.

3. Guidelines: Some instructions were given by local and global organizers in the form of handbooks and online contents. We searched for the indicated rules, procedures, and roles (organizers, mentors, participants etc.). In order to monitor the information flow, we summarized the given data to participants (for example theme, suggested tools, tips, etc.) and also the requested information at the end of the process.

4. Participants' details: These details show characteristics such as age, occupation, education, and gender.

5. Semi-structured interviews with local organizers: Three local organizers in Tehran were interviewed. These were the only organizers who were engaged in all of the jams since 
2012, so they were able to give us a complete picture of the jams' evolution since then. In these interviews, we clearly addressed the dimensions of our framework (figure 2). Organizers explained how their positive and negative experiences in each jam helped them to apply country-specific modifications in the next round. Reducing data was done by summarizing transcripts into separated lists of all tools, rules and procedures, roles, and information flow issues.

\subsection{Step 2 of qualitative analysis, displaying data}

After data reduction, the activity framework's dimensions were used to display seven information sets, as shown in table 1.

Table 1: Information sets of Tehran jams since 2012

\begin{tabular}{|c|c|c|c|c|c|c|c|}
\hline & 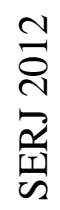 & 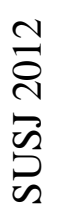 & $\begin{array}{l}m \\
\stackrel{\sim}{N} \\
\vec{\sim} \\
\frac{\pi}{\omega}\end{array}$ & 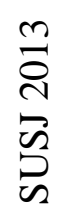 & 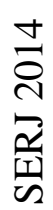 & 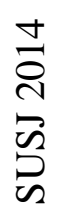 & 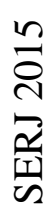 \\
\hline Global tools & \multirow{11}{*}{ 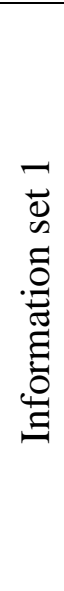 } & \multirow{11}{*}{ 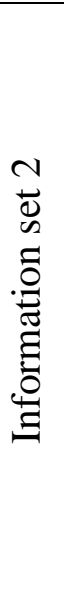 } & \multirow{11}{*}{ 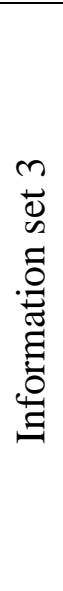 } & \multirow{11}{*}{ 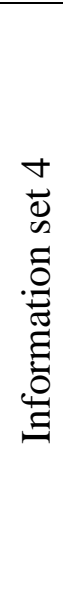 } & \multirow{11}{*}{ 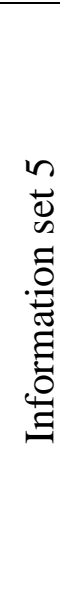 } & \multirow{11}{*}{ 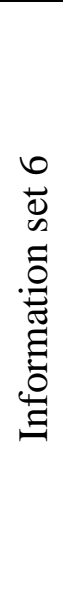 } & \multirow{11}{*}{ 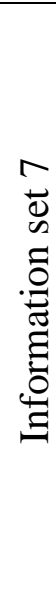 } \\
\hline Country- specific tools & & & & & & & \\
\hline Themes & & & & & & & \\
\hline Global rules and procedures & & & & & & & \\
\hline $\begin{array}{l}\text { Country-specific rules and } \\
\text { procedures }\end{array}$ & & & & & & & \\
\hline Participants & & & & & & & \\
\hline Global roles & & & & & & & \\
\hline Country-specific roles & & & & & & & \\
\hline Global designs & & & & & & & \\
\hline Country-specific designs & & & & & & & \\
\hline Information flow & & & & & & & \\
\hline
\end{tabular}

\subsection{Step 3 of qualitative analysis, drawing conclusions}

In order to draw conclusions, we applied constant comparative analysis. This method is based on comparing different sets of information (Harding, 2013), and is one of the methods suggested for synthesis of qualitative data (Eaves, 2001). According to Harding (2013), constant comparative analysis has three main steps:

1. Comparing the first two sets of information.

2. Adding other sets gradually and updating the conclusions according to the new comparisons.

3. Making final conclusions after adding all sets to the comparison. 
As figure 4 shows, we started with comparing information sets 1 and 2 (SERJ 2012 and SUSJ 2012). This comparison was labelled as comparison A, and then its results were compared with information set 3 (SERJ 2013). The same process was repeated for all sets of information.

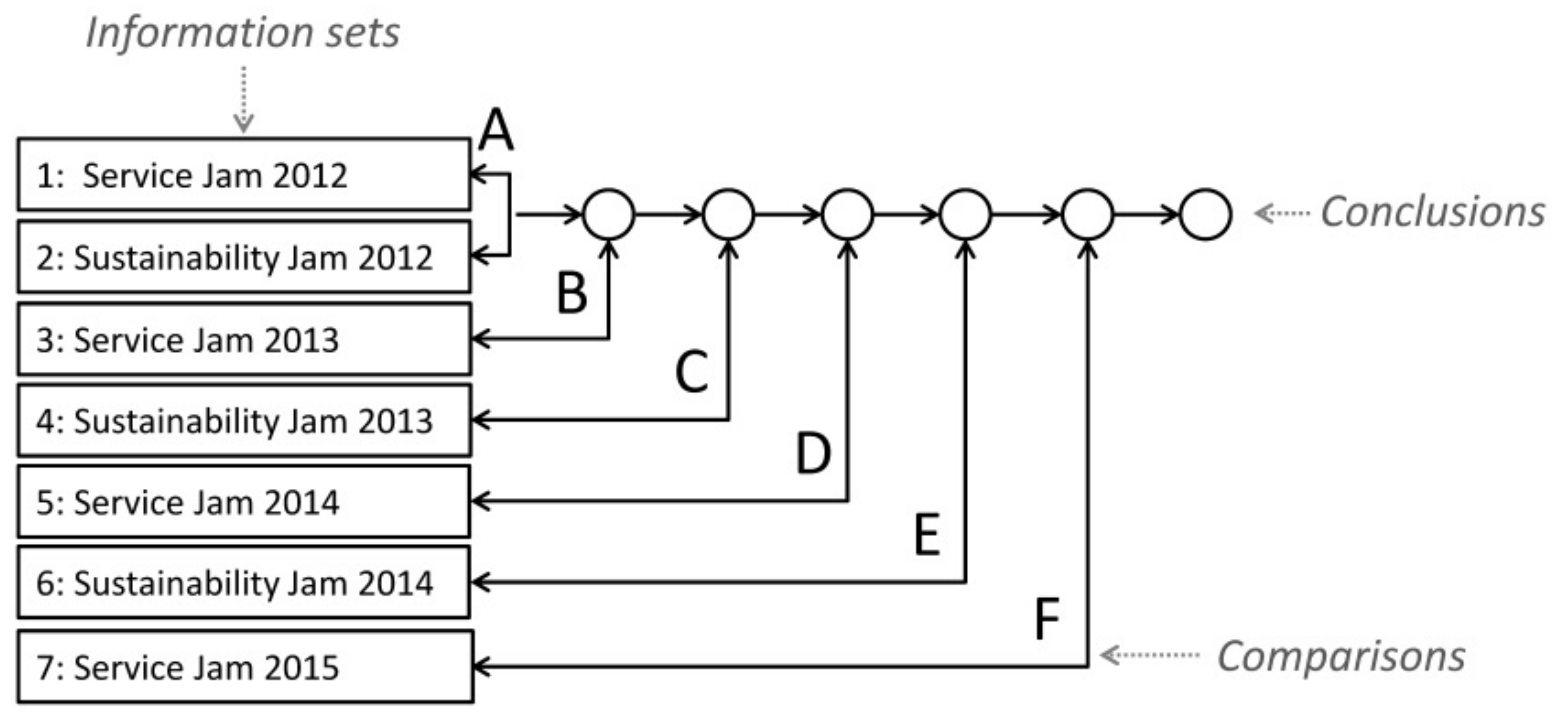

Figure 4. Constant comparative analysis

\section{Results}

This section includes an overview of the results in three steps of the qualitative analysis.

\subsection{Results of step 1 , data gathering and reduction}

The input data of this step include 51 projects (each one consists of various types of data such as images, slides and videos), Around 5000 photos taken by organizers, the contents of two websites, 14 handbooks (including both global and country-specific guidelines), demographics of 363 participants, and three interview transcripts. Table 2 shows how different data types helped us to understand the characteristics of each jam. We include a number of examples to show how data was reduced. 
Table 2. Various types of data and their contributions to our understanding of each jam

\begin{tabular}{|c|c|c|c|c|c|c|c|c|c|c|c|}
\hline & $\begin{array}{l}0 \\
0 \\
0 \\
\pi \\
0 \\
0 \\
0\end{array}$ & 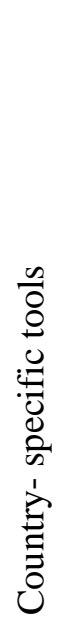 & $\underset{\mathscr{E}}{\stackrel{\mathscr{E}}{E}}$ & 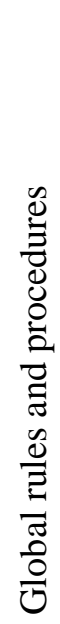 & 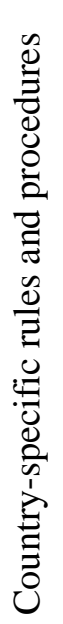 & 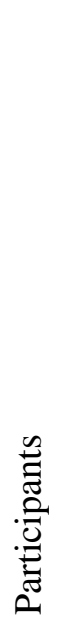 & $\begin{array}{l}\frac{\mathscr{U}}{0} \\
\stackrel{0}{0} \\
\frac{\pi}{0} \\
0\end{array}$ & 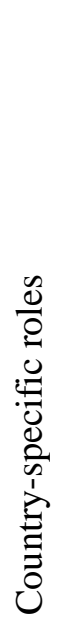 & $\begin{array}{l}\mathscr{n} \\
\tilde{D} \\
\bar{D} \\
\mathbb{U} \\
\widetilde{0} \\
0 \\
0 \\
0\end{array}$ & 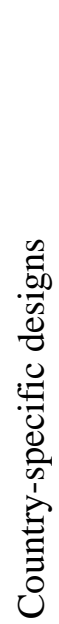 & $\begin{array}{l}3 \\
0 \\
0 \\
0 \\
.0 \\
0 \\
0 \\
0 \\
0 \\
0\end{array}$ \\
\hline Projects & $\mathrm{X}$ & $\mathrm{X}$ & & & & & & & $\mathrm{X}$ & $\mathrm{X}$ & \\
\hline Photos & $\mathrm{X}$ & $\mathrm{X}$ & & $\mathrm{X}$ & $\mathrm{X}$ & & & & & & \\
\hline Guidelines & $\mathrm{X}$ & $\mathrm{X}$ & $\mathrm{X}$ & $\mathrm{X}$ & $X$ & & $\mathrm{X}$ & $\mathrm{X}$ & & & $\mathrm{X}$ \\
\hline $\begin{array}{l}\text { Participants' } \\
\text { details }\end{array}$ & & & & & & $\mathrm{X}$ & & $\mathrm{X}$ & & & \\
\hline $\begin{array}{l}\text { Semi- } \\
\text { structured } \\
\text { interviews }\end{array}$ & $X$ & $X$ & & $X$ & $X$ & & $\mathrm{X}$ & $X$ & & & $\mathrm{X}$ \\
\hline
\end{tabular}

\subsubsection{Data reduction example 1: Projects}

As table 2 shows, projects have been used to give us some information about the global and country-specific tools used in the jams. Moreover, project contents helped us to classify the resultant designs in two categories of global and country-specific designs based on their topics and approaches. Figure 5 shows an example of a project profile accessible from the Global SERJ website. The initial data available for this project includes:

A short description of the project: This team addressed the wasteful water consumption in Tehran; therefore the outcome of this project is a country-specific design.

- Images shared by the participants showing them collaborating in idea generation and design: These images suggest that participants used affinity diagrams as a tool for organizing the ideas. This can be classified as a global tool.

- Slides and a video explaining the final design: Participants also used system diagrams and mind maps in their work. These are classified as global tools. 


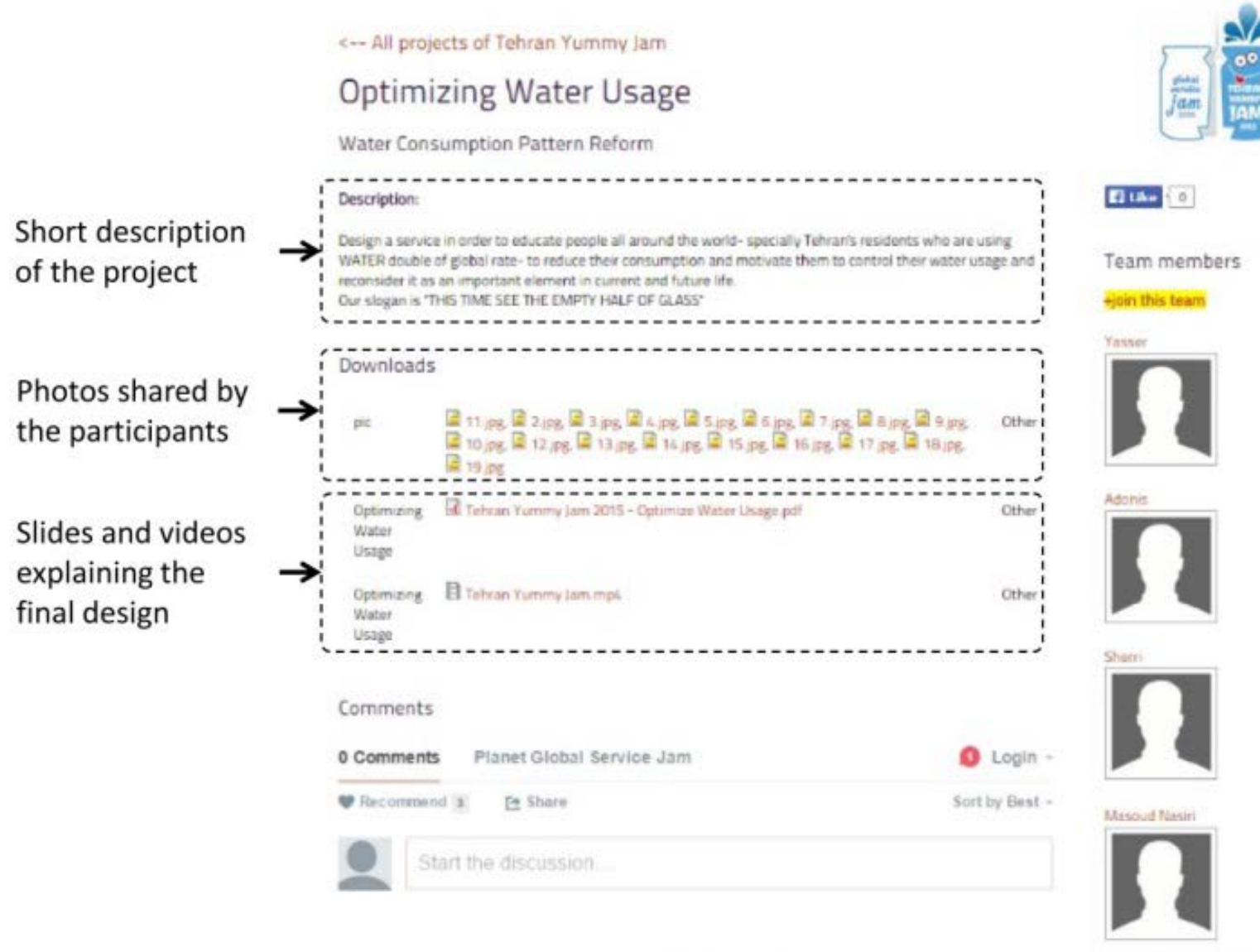

Figure 5. An example of a project profile on Global SERJ website

\subsubsection{Data reduction example 2: Participants’ details}

We found out that, except one event, women were more interested in participating in the jams. In addition, undergraduate students had a significant role in all events. We also identified a decrease in the number of participants in 2014. As we will see later in 4.3 .4 and 4.3.5 local organizers found out that increasing the number of participant do not necessarily improve the quality of designs and they preferred to conduct jams with fewer participants. A summary of the participants' specifications can be seen in table 3 . 


\begin{tabular}{|c|c|c|c|c|c|c|c|c|c|c|c|}
\hline \multirow[t]{2}{*}{ Event } & \multirow[b]{2}{*}{ 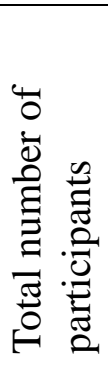 } & \multicolumn{3}{|c|}{ Occupation } & \multicolumn{5}{|c|}{ Disciplines } & \multicolumn{2}{|c|}{ Gender } \\
\hline & & 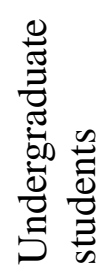 & 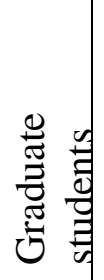 & 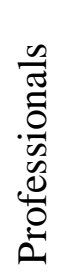 & 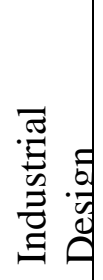 & 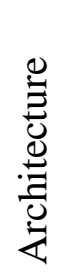 & 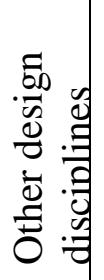 & & $\frac{\grave{\Xi}}{\stackrel{\Xi}{0}}$ & $\frac{0}{\sum^{\pi}}$ & $\frac{\mathscr{\theta}}{\underset{\Xi}{0}}$ \\
\hline SERJ12 & 37 & 27 & 5 & 5 & 34 & 1 & 2 & 0 & 0 & 12 & 25 \\
\hline SUSJ13 & 79 & 61 & 12 & 6 & 65 & 11 & 0 & 2 & 1 & 28 & 51 \\
\hline SERJ13 & 95 & 72 & 14 & 9 & 81 & 4 & 6 & 2 & 2 & 33 & 62 \\
\hline SUSJ13 & 62 & 51 & 6 & 5 & 28 & 26 & 3 & 2 & 3 & 25 & 37 \\
\hline SERJ14 & 43 & 24 & 12 & 7 & 29 & 5 & 2 & 5 & 2 & 22 & 21 \\
\hline SUSJ14 & 16 & 10 & 4 & 2 & 8 & 5 & 3 & 0 & 0 & 7 & 9 \\
\hline SERJ15 & 31 & 18 & 8 & 5 & 21 & 3 & 4 & 2 & 1 & 14 & 17 \\
\hline
\end{tabular}

\title{
4.1.3. Data reduction example 3: Semi-structured interviews
}

One of the local organizers explained what he remembered about defining the roles in SERJ 2013 (translated from Persian):

\begin{abstract}
“Based on the global headquarters' suggestions, we defined the mentor role in the SERJ 2013. Mentors had a good understanding of the jam's process and objectives, and were able to answer the participants' questions. Right before the event we asked participants to fill the registration forms in which we asked them to identify their levels of knowledge about service design and jam events. After reviewing the forms, we found out that there is a knowledge gap among the participants, so we decided to add another role called leader. Leaders were more experienced participants with good practical skills. After formation of the teams, each leader was assigned to help a particular team. Unlike mentors, leaders were actively engaged in design and practical activities.”
\end{abstract}

According to this part of the transcript, we identified mentor as a global role, and leader as a country-specific role.

\subsection{Results of step 2, displaying data}

The reduced data was used for displaying information sets for jams. Seven information sets were displayed in tables similar to table 4 . The underlined items show the changes that have been made in this round for the first time. 
Table 4: Displaying data example, SUSJ 2012 (information set 2).

\begin{tabular}{|c|c|}
\hline \multicolumn{2}{|l|}{ 2: SUSJ 2012} \\
\hline Global tools & $\begin{array}{l}\text { Online submission system - Online projects gallery - Brainstorming - Value } \\
\text { prototypes - Look and feel prototypes - Implementation prototypes - } \\
\text { Integration Prototypes - Prototyping comparison matrix - The Rough-to-Ready } \\
\text { Framework - The “Making Services Tangible” Technique - Rotating mentors - } \\
\text { Feedback in between - Help desk- Be everybody- Circuit Breakers - Business } \\
\text { model canvas - warm-ups }\end{array}$ \\
\hline $\begin{array}{l}\text { Country- specific } \\
\text { tools }\end{array}$ & Affinity Diagrams - Lectures - User Studies \\
\hline Theme & Heartbeat \\
\hline $\begin{array}{l}\text { Global rules and } \\
\text { procedures }\end{array}$ & $\begin{array}{l}\text { No commercial use - Keep it fun - Keep it moving - It is about doing, not about } \\
\text { talking - Sample time plans }\end{array}$ \\
\hline $\begin{array}{l}\text { Country-specific } \\
\text { rules and } \\
\text { procedures }\end{array}$ & $\begin{array}{l}\text { Prevent informative contents - Opening speeches - Final presentations - } \\
\text { Registration fee for lunch and refreshments - Persuading participants to go out } \\
\text { and conduct user studies }\end{array}$ \\
\hline Participants & $\begin{array}{l}79 \text { Participants in } 14 \text { Teams - Female: } 51 \text { - Male: } 28 \\
\text { Disciplines: Industrial Design: } 66 \text { - Architecture: } 11 \text { - Sustainability Strategies: } \\
1 \text { - Industrial Engineering: } 1 \\
\text { Occupations: Designers: } 6 \text { - Graduate students: } 12 \text { - Undergraduate students: } \\
61\end{array}$ \\
\hline Global roles & Organizers - Mentors - Participants - Jam doctor - Jam newshound \\
\hline $\begin{array}{l}\text { Country-specific } \\
\text { roles }\end{array}$ & Executive team - Lecturers - Photographer \\
\hline Global designs & $\begin{array}{l}\text { When the wheels get the beats: Memories on used tires in social spaces } \\
\text { Project Libro: E-books with chargeable batteries } \\
\text { One more beat: Educate user to use products longer } \\
\text { Beat Agent: Nanotech decomposers } \\
\text { LooTOo: Social place to learn about paper reuse and recycle } \\
\text { Time and life: Watch with heartbeats } \\
\text { Heart to heart: Allocate wasted time to social interactions } \\
\text { Save Beats: Eating less meat } \\
\text { Alive World: Giving beat to the dead objects } \\
\text { Come to Share: Sharing stuff we don't need }\end{array}$ \\
\hline $\begin{array}{l}\text { Country-specific } \\
\text { designs }\end{array}$ & Social Beat: Bringing social activities to traditional spaces \\
\hline
\end{tabular}




\begin{tabular}{|l|l|}
\hline & $\begin{array}{l}\text { Street Musicians in Tehran: Facilitating street music } \\
\text { The New Life: Finding a job after drug rehabilitation } \\
\text { Pulse Of Parish (POP): Restoring traditional services in new forms }\end{array}$ \\
\hline Information flow & $\begin{array}{l}\text { Pre-event information about service design and the jam. } \\
\text { Global guidelines in form of the handbook and web contents } \\
\text { Local guidelines in form of the handbook in Persian } \\
\text { A video message from the headquarters to Tehran jam's participants, } \\
\text { highlighting the objective and the procedure of jam. } \\
\text { Opening speeches by local organizers. } \\
\text { Checklist and timetable given to participants for having a more organized } \\
\text { process } \\
\text { Global communication during the event using social networks and jam's } \\
\text { website } \\
\text { Lectures } \\
\text { An overall report of jam in Persian and English after event } \\
\text { Final public presentations } \\
\text { Displaying the projects' outcomes on the jam's website }\end{array}$ \\
\hline
\end{tabular}

\subsection{Results of step 3, drawing conclusions}

The seven information sets displayed by the tables (similar to table 4) were used for constant comparative analysis. In order to avoid repetitions, only major differences are explained here. This means that, the comparisons simply explains how each jam was different from the previous rounds. The comparisons A to D (as were displayed in figure 4) revealed the following information:

\subsubsection{Comparing SERJ 2012 and SUSJ 2012 (A)}

The theme of SERJ 2012 was "Hidden Treasure" and the theme of SUSJ was "Heartbeat". The local organizers of SERJ 2012 recommended using service prototypes as a tool to the participants because there was little information about the design tools in the global guidelines. This situation has changed in SUSJ 2012, because a wide range of design, creativity, and prototyping tools were introduced in the global handbook. Organizers in Tehran encouraged teams to conduct short ethnographic research outside the jam venue in SUSJ 2012. 
No major differences can be seen in the global rules and procedures. In contrast, local organizers in Tehran add more attributes to their plan such as opening speeches, short lectures, and user studies. The number of participants shows a significant increase from 37 in SERJ 2012 to 79 in SUSJ 2012. Most participants in both jams were women and the dominant discipline was industrial design. Regarding occupation, most participants were undergraduate students.

Two global roles and two local roles were introduced for the first time in SUSJ 2012. Most designs in both jams had global approaches, while there were some country-specific designs as well. Regarding information flow, all changes were local. The organizers in Tehran tried to give more structured plans to the participants' beforehand. Therefore, lectures were conducted for filling the possible knowledge gaps between the teams; and public presentations of final designs were planned to bring more awareness to the local communities.

Conclusion: The country-specific adjustments in 2012 were about organizing jams. Some interesting demographics can be seen here, especially the dominance of female participants.

\subsubsection{Adding SERJ 2013 to the comparison (B)}

The theme of this round was "Grow^^". Most adjustments in SERJ 2013 were countryspecific. The lectures were more relevant to the jam's theme, and were given at specific points in relation to the projects' progress. Each team had a more experienced member, called leader. Teams should also give short presentations in certain checkpoints. There were information boards in the venue showing the jam's process and the teams' specifications. The closing was more formal and the final public presentations were followed by closing speeches and issuing participation certificates. In addition to the global guidelines, local organizers had an internal action plan including a detailed event program and description of all steps.

Conclusion: Similar to comparison A, we can see that the jam was more structured and more roles and steps were defined.

\subsubsection{Adding SUSJ 2013 to the comparison (C)}

SUSJ 2013's theme was “AB3”. This unclear theme was chosen intentionally to encourage diverse interpretations. In this round, online submission system was updated and the global organizers also recommended a number of checkpoints for organizing the design process. Unlike the SERJ 2013 there were few country-specific adjustments. The most important country-specific change was a more flexible action plan for organizers based on the experiences of SERJ 2013. They found out that too much discipline and check points may have drawbacks, especially considering the motto of Global SERJ and SUSJ: Keep it fun. Again, women, industrial designers, and undergraduate students were the dominant demographic segments. Of course, there were more non designer participants in this event in comparison with SERJ 2013. 
Conclusion: An important trend can be seen here. Some global adjustments are similar to the country-specific adjustments in the previous rounds. In SERJ 2012, local organizers suggested prototyping as a tool. In the next round of jams (SUSJ 2012) global organizers added multiple prototyping tools to the handbook. In SERJ 2013 checkpoints were considered by organizers in Tehran. Global organizers gave a similar suggestion in the next event (SUSJ 2013). In terms of the demographic pattern, there is no significant change. Another important development is considering more flexibility after three rounds of making jams more organized.

\subsubsection{Adding SERJ 2014 to the comparison (D)}

Most adjustments in SERJ 2014 were country-specific. This time, these changes were more about improving the outcomes rather than organizing the jam. As many designs in the previous jams were related to the information and communication technologies (ICT), a wellknown ICT firm was invited to the jam. In addition to the financial support, the firm introduced two ICT experts as specialist mentors. Five employees of the firm also joined the jam as participants. The jam was still a non-profit event, according to the global rules of SERJ.

For the first time, doing user research was mandatory for all teams, and a business model toolkit was introduced as a tool. Moreover, unlike previous jams most designs were countryspecific, and participants were almost equally distributed between males and females (22 men and 21 women). It should be noted that all participants from the ICT firm were men, and this can be a reason for this equal distribution. Based on the insights from 2013, organizers did not concentrate on attracting more participants in SERJ 2014, and the main objective was to generate high quality ideas. That is why there is a decrease in the number of participants, resulted from lower investments in advertising for attracting participants. In fact, when organizers had to deal with a large number of participants, they focused most of their efforts on organizing teams rather than improving the quality of designs.

The most important global adjustment was introducing a pictorial theme, showing a packaging design template. The global organizers claimed that pictorial themes can be understood inclusively regardless of one's native language. This idea was initially suggested by a number of local organizers around the world, including local organizers in Tehran.

Conclusion: Organizers started to pay more attention to the quality and feasibility of designs. Participation of the sponsor firm changed the demographic pattern. At the same time, we can see that global organizers changed their communication strategy to make themes more understandable for all participants around the world, regardless of their culture and mother tongue.

\subsubsection{Adding SUSJ 2014 to the comparison (E)}

Similar to SERJ 2014, the global theme was pictorial, illustrating footprints. Most countryspecific adjustments of the previous rounds were considered again. However, organizers were not successful in finding an industry link. Similar to SERJ 2014, organizers preferred to conduct the jam with fewer participants and therefore did not invest much in attracting 
participants. Again, most participants were female and design was the dominant discipline. Two user studies were mandatory, one in the first day for understanding possible users, and the other on the second day for testing low fidelity prototypes. The number of countryspecific designs was more than global designs.

Conclusion: After concentrating on organizing the jams, local organizers made more adjustments for improving the quality of outcomes, especially by decreasing the number of participants and focusing on user studies and testing low fidelity prototypes. Distribution of participants in terms of gender and profession was similar to all previous jams except SERJ 2014.

\subsubsection{Adding SERJ 2015 to the comparison (F)}

The global theme of SERJ 2015 exhibits a pictorial origami instruction. There were few differences between SERJ 2015 and SUSJ 2014. As a country-specific adjustment, all teams should deliver a business model for their designs. Demographic segments remained the same.

Conclusion: After looking at SERJ 2015 as the last round of jams, we can identify two main phases of country-specific adjustments. In the first phase in 2012 and 2013, adjustments were influential in terms of organizing the jams. During the second phase in 2014 and 2015, there was a focus on the quality of outcomes. As a result, several adjustments were made; such as conducting user studies, developing business models, and decreasing the number of participants. In general, women played an important role in most Tehran jams; however, jams were not much successful in attracting participants from non-design disciplines. Global adjustments were more visible in 2012 and 2013, but it seems that jams reached a level of maturity at that point, and therefore there were few global adjustments in 2014 and 2015. In some cases country-specific experiences and insights affected the global adjustments.

\section{Discussion}

In this section, we will look at different dimensions of the adopted activity framework, not only to discuss the research questions, but also to compare our findings with other related studies.

\subsection{Themes}

The themes of SERJs and SUSJs have been always defined by the global headquarters; however, these themes were defined in an enigmatic way to provoke participants into generating many different ideas. In order to empower the participants' imaginations and build an inclusive understanding of the themes, the themes were presented by graphics instead of words in the last events. Similar to the Peschl and Fundneider (2014) idea of enabling spaces, meanings play an important role in SUSJ and SERJ, as one theme can have a wide range of meanings for different participants. The outcomes had both global and country-specific approaches. Therefore, we can say that country-specific characteristics (and not adjustments applied by the local organizers) affected the way that participants interpreted the themes. 


\subsection{Global and country-specific tools}

In 2012 and 2013 a number of tools used for facilitating the information flow and organizing the jams in Tehran. Similar adjustments were made by global organizers in the next rounds after reviewing successful local adjustment around the world. In terms of practical tools, most concentration of local and global organizers in 2012 and 2013 was on prototyping. These prototyping tools were more helpful for understanding the scenarios of use rather than improving the technical features of designs, similar to the Van Waart et al.'s idea of participatory prototypes (2015). In 2014 and 2015, we cannot see any global adjustments in tools, and most new tools were introduced based on country-specific adjustments.

Although the role of online communication is highlighted in most related references, communications in the real world is also important (Bosch-Sijtsema and Bosch, 2014). According to the local organizers, user studies and communicating with potential users had a significant effect on the design outcomes. Another example was the physical information boards in the jams' venues. In fact, country-specific adjustments were more about what was going on in the real world, while the global organizers were more concerned about the online communications process.

\subsection{Global and country-specific designs}

SUSJ and SERJ were not different from other global jams concerning the combined global and local approaches for generating ideas (Larsen, Gunnarsson-Östling, and Westholm, 2011). After using tools such as user studies, an increase in the number of country-specific designs can be observed. The designs were not evaluated in real situations so we decided to identify the techniques for developing designs in each jam, to see how mature the final designs were. Table 5 shows an overview of the techniques. On the right side of the table, there are techniques that are more suitable for the validation and implementation of designs, such as user testing and prototypes. On the left side, there are techniques which are more being used in the early stages of a design project such as concept visualization. As mentioned, in SUSJ 2014 and SERJ 2015 conducting user studies was mandatory. That is why designs resulted from these jams had a higher level of maturity and some designs include tested working prototypes, while in SERJ 2012 there was no design on the prototype level. In general, table 5 suggests that some country-specific adjustments improved the maturity of the final designs.

It is interesting that some of these adjustments are suggested in other references as well, such as decreasing the number of participants (Ende et al., 2014), avoiding less mature concepts (Ende et al., 2014), and involving different stakeholders (Elerud-Tryde and Hooge, 2014). 
Table 5: Techniques used for developing the designs

\begin{tabular}{|c|c|c|c|c|c|c|c|}
\hline & 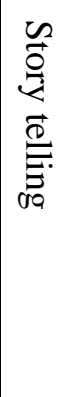 & 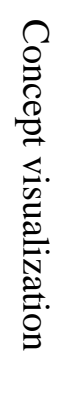 & 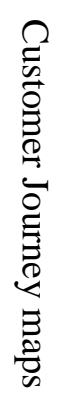 & 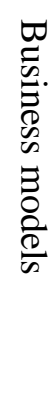 & 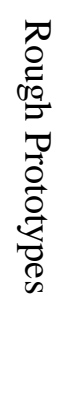 & 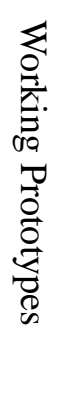 & $\begin{array}{l}C \\
\stackrel{D}{D} \\
\stackrel{D}{D} \\
\mathbb{D} \\
\stackrel{D}{\omega}\end{array}$ \\
\hline SERJ 2012 & $\bar{X}$ & $\bar{X}$ & $\bar{X}$ & & & & \\
\hline SUSJ 2012 & $X$ & $\mathrm{X}$ & $\mathrm{X}$ & & $\mathrm{X}$ & & \\
\hline SERJ 2013 & $X$ & $X$ & $X$ & $\mathrm{X}$ & $\mathrm{X}$ & & \\
\hline SUSJ 2013 & $\mathrm{X}$ & $\mathrm{X}$ & & $\mathrm{X}$ & $\mathrm{X}$ & & \\
\hline SERJ 2014 & $\mathrm{X}$ & $\mathrm{X}$ & $\mathrm{X}$ & $\mathrm{X}$ & $\mathrm{X}$ & & \\
\hline SUSJ 2014 & $\mathrm{X}$ & $\mathrm{X}$ & & & $\mathrm{X}$ & $\mathrm{X}$ & $\mathrm{X}$ \\
\hline SERJ 2015 & $\mathrm{X}$ & $\mathrm{X}$ & $\mathrm{X}$ & $\mathrm{X}$ & $\mathrm{X}$ & $\mathrm{X}$ & $\mathrm{X}$ \\
\hline
\end{tabular}

\subsection{Global and country-specific roles}

The global organizers did not define any new role after SUSJ 2013. In contrast, local organizers made changes to the roles in all jam events. Local organizers preferred to give only one clear responsibility to each role similar to what Birkinshaw et al. (2007) suggest, and as a result the number of the country-specific roles has gradually increased in the course of these seven events.

\subsection{Participants}

Number of participants increased between SERJ 2012 and SERJ 2013 (from 37 to 95), and then decreased between SUSJ 2013 and SERJ 2014 (from 62 to 31). Although having more participants can increase the quantity of generated ideas, quality of idea generation process is more controllable when few people are involved (Ende et al., 2014).Therefore, we can see that local organizers tried different numbers in the SERJs and SUSJs, and found the optimum range (around 30 participants) for the best results.

Involvement of experts and specialists from academia and industry happened in different occasions and was influential for improving the quality of designs as Elerud-Tryde and Hooge (2014) also suggested in their study. Involvement of a company and its employees in SERJ 2014 shows that there are possibilities for combining or connecting the non-profit jams such as SERJ and SUSJ to the organizational jams. However, diversity of participants, which 
is another success factor of crowdsourcing (Stieger et al., 2012) was not high in Tehran SUSJs and SERJs, because most participants were from the design community.

\subsection{Global and country-specific rules and procedures}

The objective of adjusting rules and procedures in 2012 and 2013 was to make jams more organized similar to what happened in the IBM jams (Diasio, and Bakici, 2010). In 2014 and 2015 the main aim of adjustments such as mandatory user studies was to improve the quality of designs.

Local organizers tried to find an optimum level of discipline in the jams. They started with adding more steps and detailed rules that had some advantages, but at some points they found out that extra discipline may limit the flexibility and freedom of the participants, as Stieger et al. (2012) mentioned earlier.

Most adjustments in both global and local levels were made based on empirical evidences and some adjustments on the local level were then also applied on the global level. This is similar to what Ziaie (2014) described as testing procedures in the source and target communities.

\subsection{Information flow}

Information flow can be viewed in two types of communications in SERJs and SUSJs, including the communication between the global headquarters and local organizers, and communication between the local organizers and the participants. In most related works, information flow is being viewed from the organizers - participants' communication perspective, and there are few insights about the information flow in the communication between different levels of organizers. The global organizers' main effort was to facilitate the information flow, by persuading local organizers and participants to share their updates and follow other jams activities. They also tried to make the themes culturally inclusive by shifting to the pictorial themes since SERJ 2014. They only used online tools for exchanging the information.

The strategy of local organizers was somehow different. They increased the diversity of channels and sources of information. In addition to the online channels, they considered conventional tools such as lectures and information boards. They also tried to specialize the sources of information by using specialist mentors, inviting an ICT firm, and defining the topics of lectures based on different steps design process. We did not see anything similar to what Birkinshaw et al. (2007) highlight as the challenges of discontinuous innovations, such as difficulties in communication, concerns about sharing the information, and resistance against inviting external stakeholders. A possible reason for this situation could be the nonprofit nature of SERJs and SUSJs.

\section{Conclusion}

In this study multiple sources of data including projects, photos, guidelines, participants' details, and semi-structured interviews were used to understand how Tehran's SERJs and 
SUSJs evolved between 2012 and 2015. In order to analyse these heterogeneous sets of data, a three step qualitative analysis was used. In addition, based on an adopted version of Engestrom's (2000) activity theory framework, we looked at certain dimensions of jams including themes, tools, designs, roles, participants, rules and procedures, and information flow on both global and country-specific levels. In response to RQ1, we identified some patterns of changes in all mentioned dimensions. The most important changes were the changes made by local organizers on a country-specific level. Therefore considering RQ2, we can say that the evolution of Tehran SERJs and SUSJs since 2012 was mainly influenced by country-specific adjustments rather than the global adjustments.

Because of the country-specific adjustments, especially introduction of new rules, designs generated in the final rounds of SERJs and SUSJs were more mature and benefited from user studies, prototypes and business models. However, as these jams were non-profit and planned for increasing the awareness rather than producing real services and products, further evaluation of outcomes (to be more specific, designs), and their relationships with the country-specific adjustments is not possible.

In response to RQ3, we can highlight some lessons learned from these jams that can be insightful for other similar social events in country-specific settings:

- Applying successful country-specific adjustments in other contexts: Participants' designs are the only outcome of the jams that are viewable on the SERJ and SUSJ websites. However, another valuable outcome is the way that jams were organized and conducted in different countries. This information is actually not available to everyone and global organizers did not managed to collect and present it in a systematic way. Earlier in this paper, we mentioned a number of examples from SERJ and SUSJ where global organizers were inspired by successful local adjustments. As a result, local organizers should be encouraged to effectively communicate and share their tools, action plans and other innovative adjustments. This practice can improve the overall experience of jams around the world.

- Iterative social design: We can see that local organizers have been continuously working on improving the events using a wide range of adjustments. Sometimes these adjustments were contradictory, as they were trying to find an optimum point by try and error. For example, they tried to increase the number of participants in the early jams, but finally they decided to organize the jams with around 30 participants as an optimum number that can ensure both quality and quantity of designs.

- Using adopted activity framework as an analytical tool: In order to improve the jams experience through the iterative social design process, organizers need to evaluate each jam event systematically. The adopted activity framework illustrated in figure 2 can be used for identifying, classifying and comparing different attributes of the jams or other similar social design activities, similar to the way that we used it in this study.

- Improving collaboration in both physical and online environments: Online collaboration can be viewed as the core activity of most innovation jams. However, Tehran's SERJs and SUSJs also benefited from some adjustments for facilitating collaboration in physical environments.

- Identifying influential participants: Some participants can be viewed as catalysts for innovation jams. Understanding existing social and cultural trends may help the 
organizers to identify those participants. As an example, we observed the significant role of the female participants in Tehran jams. A similar pattern can be seen in the Iran's higher education as women's entrance into the universities and percentage of female graduates have been higher than men in the recent years (Povey and RostamiPovey, 2016).

\section{Research Limitations}

We found out that country-specific adjustments can play the main role in shaping the global jams, and this can be a basis for posing research questions for investigating similar activities in different countries and communities, and even cross-cultural studies. However, similar to the most qualitative studies, what we found about Tehran SERJs and SUSJs between 2012 and 2015 are not easily extendable to other similar activities.

Our analysis was based on both SERJs and SUSJs because of the similarity of these events, and also accessing to few rounds of these contemporary events. However, it should be noted that the objectives of SERJs and SUSJs were different. Therefore, if accessing to multiple rounds of each jam was possible analysing only one jam probably would give us more accurate findings.

In addition, without any doubt researchers' own interpretations had a great role in the qualitative analysis, especially in the constant comparative analysis. Therefore, other researchers might be able to extract wider range of findings using the same data sets. However, we believe that this was a starting point for exploring jams as a new form of social design and innovation, especially in less explored social and cultural contexts like Iran.

\section{References}

What's a Jam? [online] http://planet.globalsustainabilityjam.org/content/whats-jam (Accessed 07 August 2015).

What is a Jam? [online] http://planet.globalservicejam.org/content/whats-jam (Accessed 28 July 2015).

Barra, G. (2012) Chinese craft project: a product service system for traditional craftsmanship recognition inside Shanghai. MSc Thesis, Politecnico Di Milano, Milan, Italy.

Berliner, P. (1994) Thinking in jazz the infinite art of improvisation, University of Chicago Press, Chicago.

Birkinshaw, J. Bessant, J. and Delbridge, R. (2007) 'Finding, forming, and performing: Creating networks for discontinuous innovation', California Management Review, Vol. 49 No. 3, pp. 67-84.

Bjelland, O.M. and Wood, R.C. (2008) 'An Inside View of IBM's' Innovation Jam", MIT Sloan management review, Vol. 50 No. 1, pp. 32-40. 
Bosch-Sijtsema, P. and Bosch, J. (2014) 'User Involvement throughout the Innovation Process in High-Tech Industries', Journal of Product Innovation Management, Vol. 32 No. 5, pp. 793-807.

Callaghan, C.W. (2014) 'R\&D Failure and Second Generation R\&D: New Potentialities', Mediterranean Journal of Social Sciences, Vol. 5 No. 3, pp. 11.

Carlsson, A. et al (2015) 'Sustainability Jam Sessions for vision creation and problem solving', Journal of Cleaner Production, Vol. 98, pp. 29-35.

Corsi, P. and Neau, E. (2015) Innovation Capability Maturity Model, 1 ed., ISTE, London.

Craig, D.V. (2009) Action research essentials, Jossey-Bass, San Francisco.

Creswell, J.W. (2014) 'Research questions and hypotheses', Research design : qualitative, quantitative, and mixed methods approaches, SAGE Publications, Thousand Oaks, pp. 139154.

Diasio, S. and Bakici, T. (2010) 'A process view of open innovation', Management, Vol. 24 No. 510, pp. 521-2.

Eaves, Y.D. (2001) 'A synthesis technique for grounded theory data analysis', Journal of advanced nursing, Vol. 35 No. 5, pp. 654-663.

Edwards, A. (2000) 'Looking at action research through the lenses of sociocultural psychology and activity theory', Educational Action Research, Vol. 8 No. 1, pp. 195-204.

Elerud-Tryde, A. and Hooge, S. (2014) 'Beyond the generation of ideas: virtual idea campaigns to spur creativity and innovation', Creativity and Innovation Management, Vol. 23 No. 3, pp. 290-302.

Ende J., Frederiksen, L. and Prencipe, A. (2014) 'The front end of innovation: Organizing search for ideas', Journal of Product Innovation Management, Vol. 32, No. 4, pp. 482-487.

Engestrom, Y. (2000) 'Activity theory as a framework for analyzing and redesigning work', Ergonomics, Vol. 43 No. 7, pp. 960-974 .

Ghorashi, R. and Zangeneh, H. (2014) 'Iran at a crossroads', in Looney, R.E. (Ed.), Handbook of Emerging Economies, Routledge, New York, pp. 420-457.

Harding, J. (2013) Qualitative data analysis from start to finish, SAGE, London; Thousand Oaks.

Helander, M. et al (2007) 'Looking for great ideas: Analyzing the innovation jam', Proceedings of the 9th WebKDD and 1st SNA-KDD 2007 workshop on Web mining and social network analysis, ACM, pp. 66-73. 
Hewing, M. (2014) Collaboration with potential users for discontinuous innovation : experimental research on user creativity, Springer Gabler, Wiesbaden.

Huberman, A.M. and Miles, M.B. (1994) 'Data management and analysis methods', in Lincoln, N. (Ed.), Handbook of qualitative research, Sage Publications, Inc, Thousand Oaks, pp. 428-444.

Huff, A.S. et al (2013) Leading open innovation, MIT Press, Cambridge.

Keinz, P. et al (2012) 'Designing the organization for user innovation', Journal of Organization Design, Vol. 1 No. 3, pp. 20-36.

Larsen, K. et al (2011) 'Environmental scenarios and local-global level of community engagement: Environmental justice, jams, institutions and innovation', Futures, Vol. 43 No. 4, pp. 413-423.

Laubacher, R. (2012) 'Entrepreneurship and Venture Capital in the Age of Collective Intelligence', Bodde, DL, Caron, H. St. John (Eds.) Chance and Intent-Managing the Risks of Innovation and Entrepreneurship, Routledge, London.

Lo, K.P.Y. (2014) 'Hybrid Touchpoints for Relational Service in Social Innovation: A Case Study of “Eat Me!”', NordDesign 2014 Conference (10th International Conference), Design Research Society, Espoo, Finland, pp. 437-447.

McMahon, M. and Bhamra, T. (2012) 'Design Beyond Borders’: international collaborative projects as a mechanism to integrate social sustainability into student design practice', Journal of Cleaner Production, Vol. 23 No. 1, pp. 86-95.

O’Neill, J. and Stupnytska, A. (2010) The rise of the BRICs and N-11 consumer. Strategy Series, Goldman Sachs, London.

Pearson, B. (2011) Pre-commerce how companies and customers are transforming business together, John Wiley \& Sons, San Francisco.

Peschl, M.F. and Fundneider, T. (2014) 'Designing and Enabling Spaces for collaborative knowledge creation and innovation: From managing to enabling innovation as socioepistemological technology', Computers in Human Behavior, Vol. 37, pp. 346-359.

Povey, T. and Rostami-Povey, E. (2016) Women, Power and Politics in 21st Century Iran, Routledge, New York, pp. 47-48.

Römer, M. et al (2011) 'Jams as emerging practice of innovation communities: The case of the Global Service Jam', Lecture Notes in Informatics LNI, Vol. 192, [online] http://citeseerx.ist.psu.edu/viewdoc/download?doi=10.1.1.259.4347\&rep=rep1\&type=pdf (Accessed 23 November 2015). 
Rubin, B. (2012) The Middle East: A Guide to Politics, Economics, Society and Culture, Routledge, New York.

Sohng, S.S.L. (1996) 'Participatory research and community organizers', J. Soc. \& Soc. Welfare, Vol. 23, pp. 77.

Stieger, D. et al (2012) 'Democratizing strategy: How crowdsourcing can be used for strategy dialogues', California Management Review, No. 54, pp. 44-68.

Turkel, G. and Theodorakopoulou, S. (2015) Open innovation in practice: Based on two case studies from companies in the automotive and telecommunication industry. Chalmers University of Technology, Göteborg, Sweden.

Van Waart, P. et al (2015) 'Participatory Prototyping for Future Cities', 4th Participatory Innovation Conference 2015, The Hague University of Applied Sciences, The Hague, The Netherlands, pp. 337.

Ziaie P. (2014) 'A Model for Context in the Design of Open Production Communities', ACM Computing Surveys (CSUR), Vol. 47 No. 2, pp. 29. 